\title{
DANOS À SAÚDE DECORRENTES DE EXPOSIÇÃO À POLUIÇÃO ELETROMAGNÉTICA: ESTUDO DA APELAÇÃO CÍVEL No 1.0123.10.038116-9/002
}

\author{
HEALTH DAMAGE DUE TO THE EXPOSITION OF ELECTROMAGNETIC POLLUTION:
} STUDY OF CIVIL APPEAL $N^{\circ}$ 1.0123.10.038116-9/002

Beatriz Souza Costa* Vivian Lacerda Moraes**

RESUMO: O presente artigo tem como intuito proceder a um estudo problematizante e crítico acerca dos fundamentos decisórios do acórdão extraído da Apelação Cível de número 1.0123.10.038116-9/002, e julgamento realizado pela $5^{\mathrm{a}}$ Câmara Cível do Tribunal de Justiça de Minas Gerais na qual se nega o pedido de retirada de rádio-base de determinado bairro da cidade de Capelinha/MG por não se entender provado serem nocivos os níveis de radiação eletromagnética emitidos. Preliminarmente será apresentada uma análise de conceitos básicos acerca do tema ondas eletromagnéticas e sua emissão no meio ambiente. No decorrer do estudo será abordado o tema dos possíveis efeitos da radiação eletromagnética para a saúde humana. Optou-se pela técnica de pesquisa bibliográfica, por meio da análise crítica de um julgado, assim como de textos referentes ao tema, bem como o método dedutivo. Apesar de as informações fornecidas pela ANATEL afirmarem não serem nocivos os níveis de radiação emitidos pelas rádio-bases, diversos estudos apontam para um sentido diverso, dessa forma, permitir que uma antena com tal potencial poluidor permaneça em bairro residencial seria arriscado à saúde humana.

PALAVRAS-CHAVE: Poluição Eletromagnética. Meio Ambiente. Ondas Eletromagnéticas. Direito à Saúde. Ministério Público do Estado de Minas Gerais.
ABSTRACT: The present article aims to proceed with a problematizing and critic study about the decision-making fundaments of the rulings extracted from the Civil Appeal numbered 1.0123.10.038116-9/002, and trial realized by the $5^{a}$ Civil Chamber of the Justice Court of Minas Gerais in which it refuses the request of removal of cell site from the determined district of Capelinha/MG for not perceiving proved harmful the levels of electromagnetic radiation emitted. Preliminarily it will present an analysis of the basic concepts of the theme electromagnetic waves and its emission on the environment. During the study will be approached the theme of possible effects of the electromagnetic radiation to human health. Bibliographic research was the chosen technique, by means of critical analysis of a ruling, as well as texts referring to the theme, along the deductive method. Despite the information provided by ANATEL claiming not being noxious the levels of radiation emitted by cell sites, several studies point to a diverse direction, in this way, allowing that a antennae with such polluting potential remain in an residential district would be risky to human health.

KEYWORDS: Electromagnetic Pollution. Environment. Electromagnetic Waves. Health Rights. State of Minas Gerais.

SUMÁRIO: Introdução. 1 Ondas Eletromagnéticas, Linhas de Alta Tensão, Campos Eletromagnéticos Domésticos e Torres de Telefonia Móvel. 1.1 Ondas Eletromagnéticas Limpas e Sujas. 1.2 As Linhas de Alta Tensão e os Campos Eletromagnéticos Domésticos. 1.2.1 Equipamentos Elétricos Domésticos. 1.3 As Antenas de Celulares e o Uso de Aparelhos de Telefonia Móvel. 2 A Apelação Cível N 1.0123.10.038116-9/002 do Tribunal de Justiça de Minas Gerais. Considerações Finais. Referências.

\footnotetext{
* Doutora em Direito pela Universidade Federal de Minas Gerais (UFMG). Professora do Programa de Mestrado em Direito Ambiental e Desenvolvimento Sustentável da Escola Superior Dom Helder Câmara, Minas Gerais. Pró-reitora de pesquisa da Escola Superior Dom Helder Câmara, Minas Gerais.

** Mestranda em Direito Ambiental e Desenvolvimento Sustentável da Escola Superior Dom Helder Câmara, Minas Gerais. Especialista em Direito Processual Civil pelo Instituto de Educação Continuada da Pontifícia Universidade Católica de Minas Gerais (PUC Minas).
} 


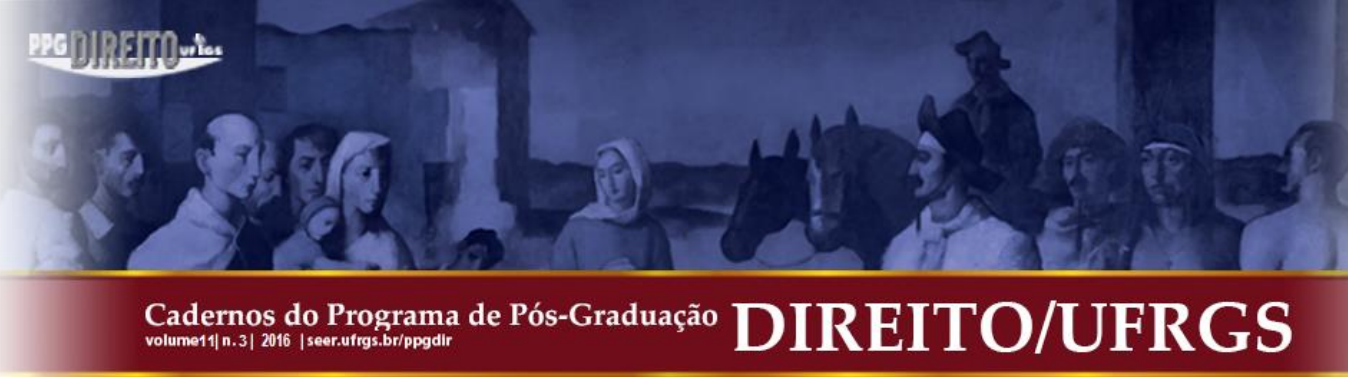

\section{INTRODUÇÃO}

$\mathrm{Na}$ atualidade, produtos elétricos e eletrônicos são indispensáveis para a vida cotidiana do ser humano. Todos os dias novos aparelhos são adquiridos, novas tecnologias são lançadas e mais e mais ondas eletromagnéticas são disseminadas descuidadamente no ambiente.

Sabe-se que o excesso de ondas eletromagnéticas dispersos no ambiente todos os dias sobrecarrega o organismo humano e, segundo estudos, podem afetar o corpo humano de diversas formas.

Não obstante a evolução tecnológica e a tentativa das empresas de diminuis a emissão de ondas eletromagnéticas e microondas, ainda encontramo-nos em um ambiente bastante poluído. E, da mesma forma, os estudos acerca das consequências desta exposição para a saúde humana não param de avançar a todo instante, a fim de analisar e comprovar as reais extensões dos problemas causados à boa saúde humana.

Diante disso, em um primeiro momento, abordar-se-á conceitos científicos de ondas eletromagnéticas, ondas eletromagnéticas sujas e limpas, linhas de alta tensão e campos eletromagnéticos domésticos, equipamentos elétricos e, por ultimo rádios-base ou torres de telefonia celular.

O tema em questão possui inegável importância tanto prática quanto social, vez que se relaciona com o direito constitucional à saúde e ao meio ambiente ecologicamente equilibrado. Nesse contexto, analisou-se a apelação cível $\mathrm{n}^{\mathrm{o}}$ 1.0123.10.038116-9/002, do Tribunal de Justiça de Minas Gerais, de julgamento correspondeu à $5^{\mathrm{a}}$ Câmara Cível e analisou a possibilidade de retirada da rádio-base do bairro das Acácias em Capelinha/MG.

Seriam as ondas eletromagnéticas efetivamente nocivas à saúde humana? A fim de chegar aos objetivos pretendidos utilizou-se como técnica de pesquisa bibliográfica, bem como pelo método o dedutivo. Tendo-se como facilitador da análise das opiniões dos doutrinadores, bem como jurisprudenciais o método dedutivo.

Vive-se em um período de modernidade tal que os avanços tecnológicos mostram-se cada vez mais rápidos. Ao que parece, todos os dias novas tecnologias surgem e são disponibilizadas no mercado consumidor, e acabam por também alimentar o frenesi consumista que parece estar arraigado na sociedade atual.

A existência de novas tecnologias e o aumento massivo de seu uso pelo ser humano propicia um crescimento significativo e alarmante das emissões de ondas eletromagnéticas. 


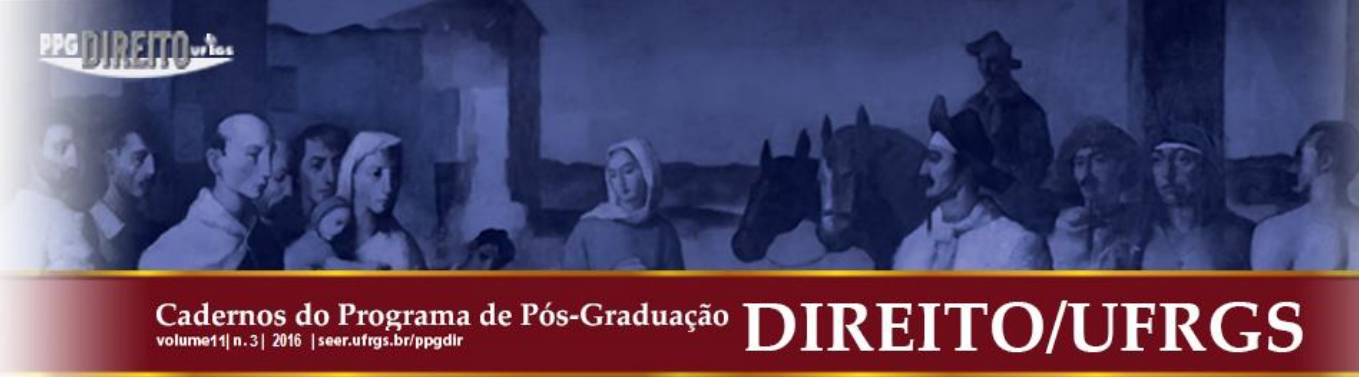

Tais ondas como ver-se-á adiante, subdividem-se em ondas de alta e baixa frequência ${ }^{1}$, a depender do número de vezes que a corrente elétrica muda o seu sentido.

Desta feita, buscou-se analisar os documentos disponíveis a fim de tentar solucionar tais questões.

\section{ONDAS ELETROMAGNÉticas, LiNHAS DE ALTA TENSÃo, CAMPOS ELETROMAGNÉTICOS DOMÉSTICOS E TORRES DE TELEFONIA MÓVEL}

Ondas magnéticas não são criações humanas, o próprio planeta Terra, naturalmente produz certo nível de carga eletromagnética importante para seu adequado funcionamento. Como explica Lopes (2014) a terra seria como uma grande bateria que se recarrega por meio da energia que recebe do sol constantemente, uma vez que os raios provenientes da atmosfera e de seu próprio núcleo em fusão acabam por coloca-la em constante e permanente descarga. Assim como o corpo humano que funciona emitindo pequenas quantidades de ondas eletromagnéticas que se mostram essenciais para a mantença de seus processos bioquímicos e são utilizadas para auferir o estado de saúde de nosso organismo.

Ondas eletromagnéticas formam-se por meio da junção de dois campos distintos, os elétricos ${ }^{2}$ e os magnéticos ${ }^{3}$, um perpendicular ao outro e que viajam em determinada direção. Tais ondas têm como característica e objetivo transportar energia no espaço.

\subsection{Ondas Eletromagnéticas Limpas e Sujas}

As ondas produzidas nas centrais elétricas são consideradas limpas, por terem comprimentos suaves e simétricos, ou seja, metade da onda é positiva e metade da onda é negativa. Essa onda "limpa" seria a responsável por criar os campos magnéticos de alta

\footnotetext{
${ }^{1}$ Frequência [...] descreve o número de oscilações ou ciclos por segundo de maneira que $1 \mathrm{~Hz}$ (hertz) corresponde a 1 ciclo por segundo (BOITEUX. E; BOITEUX. NETTO, 2008, p. 35). São consideradas ondas de baixa frequência aquelas emitidas em torno de $50 / 60 \mathrm{~Hz}$, e ondas de alta frequência aquelas emitidas em mega $\mathrm{Hz}$ ou giga $\mathrm{Hz}$.

${ }^{2}$ Campos elétricos são uma parte dos campos eletromagnéticos. Eles são produzidos pela presença de cargas elétricas e podem ser medidos em volts por metro $(\mathrm{V} / \mathrm{m})$. Quando um objeto acumula carga elétrica, esta faz com que outras cargas do mesmo sinal ou de sinal oposto experimentem uma repulsão ou atração, sendo a intensidade destas forças denominada tensão elétrica ou voltagem, medida em Volts (BOITEUX E.; BOITEUX. NETTO, 2008, p. 34).

${ }^{3}$ Campos magnéticos são produzidos quando há cargas elétricas em movimento, ou seja, correntes elétricas, determinando o movimento destas cargas. Uma lâmpada ligada na tomada, tal qual uma torneia aberta, movimenta energia (BOITEUX, E.; BOITEUX, NETTO., 2008, p. 34).
} 


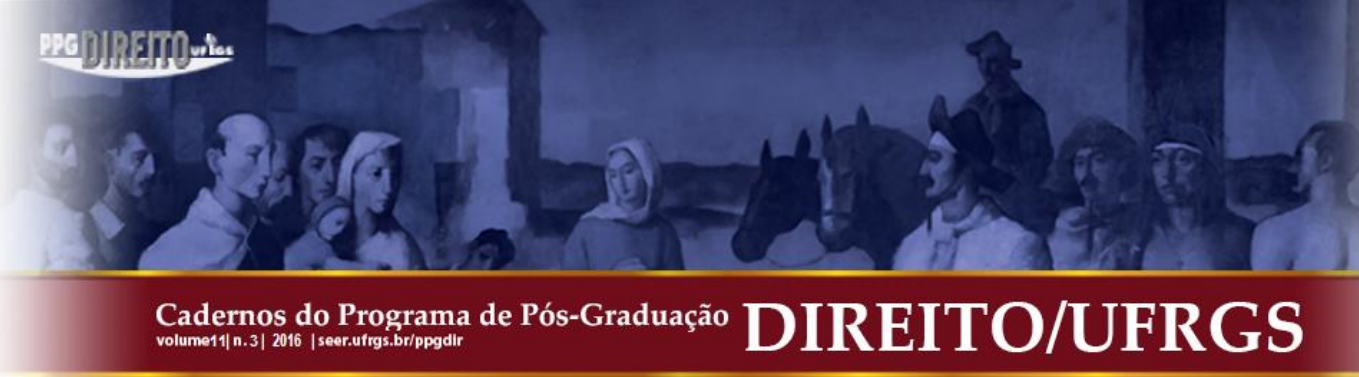

Dessa forma, pode-se perceber que, as linhas de alta tensão, por produzirem amplos campos magnéticos e seus transformadores serem responsáveis pela criação de zonas de campos eletromagnéticos elevados são grandes responsáveis pela geração de poluição ambiental. Tal poluição gerada mostra-se um grande problema da sociedade contemporânea, uma vez que não é possível que nos vejamos sem o uso da eletricidade ou os aparelhos que dela necessitam. A cada segundo novas tecnologias movidas à eletricidade são produzidas, e acabam por alimentar também a sede consumista, aumentando a emissão de ondas eletromagnéticas à nossa volta.

Viver perto de linhas de alta tensão, na vizinhança ou muitas vezes "debaixo" delas pode acarretar riscos graves à saúde das pessoas. Por isso, quem vive ou pretende viver em tais locais precisa estar ciente dos riscos e implicações de tal situação. No entanto, as pesquisas feitas neste campo, apesar de demonstrarem que há sérias consequências para a vivência nessas áreas, ainda não conseguiram encontrar respostas concretas sobre o potencial maléfico para a saúde humana. Conforme relata Lopes (2104) a vida perto das linhas de alta tensão ainda se mostra um assunto de natureza controversa, pois existem muitas pessoas que moram nesses lugares, ou mesmo embaixo das linhas de alta tensão, e afirmam nada sofrer, eventualmente por não conseguirem relacionar os efeitos em sua saúde com as causas mas, principalmente, por não possuírem outras opções de moradia, não tendo um outro local para onde ir.

Uma importante fonte produtora de campos eletromagnéticos são os equipamentos elétricos de natureza doméstica.

\subsubsection{Equipamentos Elétricos Domésticos}

Cada aparelho elétrico que ligamos todos os dias à rede elétrica gera radiação eletromagnético $^{5}$ e, portanto, nos expõe mesmo que potencialmente aos campos eletromagnéticos. Afirma Lopes (2014) que os aparelhos a oferecerem maior preocupação seriam aqueles que usamos todos os dias e por um período de tempo maior, assim como aqueles que utilizamos mais perto do corpo ou que precisamos segurar com as mãos.

\footnotetext{
${ }^{5}$ Sob a perspectiva quântica a radiação eletromagnética é o resultado da emissão de pequenos pulsos de energia, enquanto que sob uma perspectiva ondulatória, a radiação eletromagnética se propaga na forma de ondas formadas pela oscilação dos campos elétrico e magnético. (RIO GRANDE DO SUL. Centro Estadual de Pesquisas em Sensoriamento Remoto e meteorologia).
} 


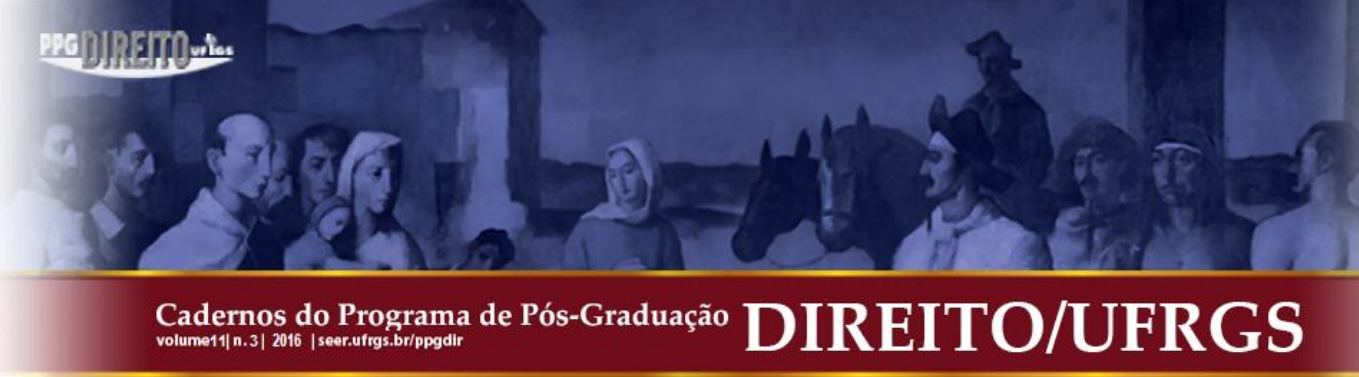

Apesar de não considerarem como assunto relevante as emissões de radiações eletromagnéticas provenientes das televisões, rádios e televisões digitais, certo é que, mesmo estando em muito baixa frequência, tais emissões contribuem para a poluição eletromagnética do ambiente doméstico. Ao tratar do tema referente às televisões, rádios e televisões digitais, uma publicação da Organização Mundial a Saúde, citada por Lopes (2014) diz que de fato, devido a suas frequências mais baixas da gama das radiofrequências, o corpo humano absorve até cinco vezes mais sinal do que o recebido das antenas de celular. Desta forma, mesmo emitindo radiações em baixos níveis, esses aparelhos podem oferecer um alto grau de poluição ambiental de natureza eletromagnética, bem como riscos a saúde daqueles que os utilizam.

Outro aparelho doméstico que pode oferecer um alto risco à saúde em virtude da emissão de radiações eletromagnéticas é a chamada "babá eletrônica". Os bebês, para Lopes (2014), por serem ainda muito pequenos, tornam-se mais susceptíveis às emissões de radiações eletromagnéticas. Tal fato ocorre porque suas células encontram-se em ativo crescimento e seu cérebro ainda está na primeira fase de desenvolvimento. Dessa maneira, o cuidado com esses seres humanos, ainda em estágios primários de desenvolvimento biológico devem ser maiores e a exposição à poluição ambiental eletromagnética oferecida pelas babás eletrônicas colocadas muito próximas aos berços pode acarretar danos à saúde e ao pleno desenvolvimento dos bebês.

Outra grande fonte emitente de ondas eletromagnéticas na atualidade e parte integrante da vida moderna são as antenas de celulares e, por consequência, o uso de aparelhos de telefonia móvel.

\subsection{As Antenas de Celulares e o Uso de Aparelhos de Telefonia Móvel}

Um item que parece ser indispensável à vida de praticamente todo ser humano moderno é o aparelho de telefona móvel. Para todo lugar que se olha é possível enxergar não uma, mas várias pessoas utilizando-se dessa comodidade tecnológica de várias formas, seja efetuando ligações, ouvindo músicas, acessando à internet por meio dos dados móveis de internet, mandando mensagens, jogando. Quase nunca uma pessoa possuidora de um aparelho desses se afasta por mais de uns poucos metros do celular e, há aqueles que, quando esquecem 
o dispositivo de telefonia móvel em algum lugar chegam aos extremos de sentirem-se praticamente nus, ou transportados para a "era das cavernas". Nesse sentido

\begin{abstract}
O número de usuários de telefonia celular aumenta a cada ano. Consequentemente, cada vez mais são instaladas torres, antenas e outras estruturas complexas que vêm sendo fixadas predominantemente nos centros urbanos de todo o país. Além do aumento no número de instalações de ERBs (estações rádio base) há que se considerar que a potência emitida por tais estruturas aumenta cada vez mais para o atendimento da crescente demanda (PADUELI; GOUVEIA, 2010, p. 1).
\end{abstract}

Cada vez mais aumenta o número de usuários de telefonia móvel e, com ela soma-se o número de antenas instaladas em todo país e, consequentemente, expande-se a produção de campos eletromagnéticos que emitem microondas. Apesar dos estudos e alertas que se tem feito, tais torres cada dia mais são instaladas em bairros residenciais e topos de prédios. Os valores oferecidos pelas empresas de telefonia a título de "aluguel" desses espaços é alto e faz com que seja questionado se os alugueres exorbitantes voluntariamente oferecidos pelas companhias telefônicas não estaria, de alguma forma, ligado à consciência dos males causados à saúde pela poluição ambiental eletromagnética.

A utilização massiva da telefonia móvel aumenta em muito a poluição eletromagnética no ambiente uma vez que o sistema móvel de celular não faz uso de cabos e fios para transmitir seus sinais, usando em contrapartida, o próprio ar, por meio do espectro eletromagnéticos ${ }^{6}$. De forma mais clara

As estações de rádio base (antenas) no sistema de telefonia móvel celular utilizam o serviço de transmissão de dados através da energia, isto é, por meio do espectro eletromagnético, sem o emprego de fios, permitindo ao usuário fazer e receber chamadas em seu telefone celular sem qualquer dificuldade (ALMEIDA, 2010. p. 22).

A partir do momento que se liga um aparelho de celular ele, automaticamente se conecta com a torre mais próxima e com ela abre um "canal" de comunicação que possibilita que chamadas sejam feitas. No momento em que se efetua a ligação e, portanto, usa-se a torre mais próxima como um meio de se conectar a outra torre que, consequentemente fará a conexão com o aparelho para o qual se destina a ligação é que o nível de radiação do aparelho celular se torna mais alto e, portanto, o corpo recebe uma carga maior. As zonas de alcance das torres de celulares são cada vez maiores, uma vez que as grandes operadoras têm como

6 O espectro eletromagnético é a distribuição da intensidade da radiação eletromagnética com relação ao seu comprimento de onda ou frequência. (INSTITUTO DE FÍSICA DA UNIVERSIDADE FEREDAL DO RIO GRANDE DO SUL).

Cadernos do Programa de Pós-Graduação em Direito PPGDir./UfRgS | Edição Digital | Porto Alegre | Volume XI | Número 3 | 2016 | P. 80 -98 


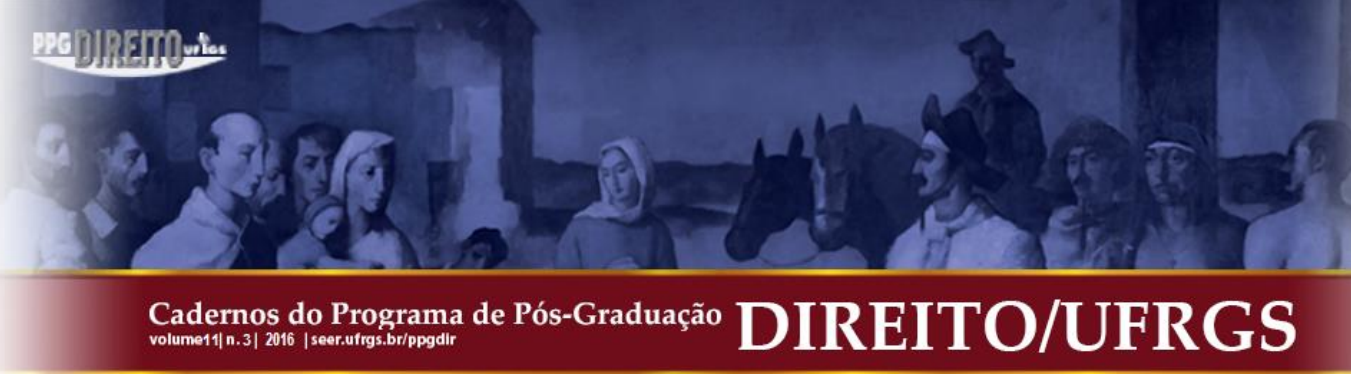

finalidade fazer com que um aparelho seja rapidamente capitado pela zona de alcance de uma torre ao deixar a zona da torre anterior.

A radiação emitida por um aparelho de celular pode atingir grandes picos quando seu usuário encontra-se nas bordas das zonas de uma torre de telefonia, no final da área de cobertura, pois nesse ponto, ao não ter outra torre na qual se conectar, e estando muito distante da torre, o impulso magnético para chegar à torre se torna maior. Sendo maiores os impulsos magnéticos, maior a potencialidade de danos à saúde do usuário da telefonia móvel.

Após perpassar brevemente acerca dos conceitos de ondas eletromagnéticas, bem como suas emissões por meio de torres de alta tensão, campos eletromagnéticos domésticos e, o que talvez seja o maior emissor da atualidade, as radio-bases, passa-se à análise da apelação cível $\mathrm{n}^{\mathrm{o}}$ 1.0123.10.038116-9/002 do Tribunal de Justiça de Minas Gerais originada do inquérito civil proveniente da comarca de Capelinha/MG.

\section{A APELAÇÃO CÍVEL N N $^{\circ}$ (123.10.038116-9/002 DO TRIBUNAL DE JUSTIÇA DE MINAS GERAIS}

Apesar de o planeta emitir a todo momento pequenas quantidades de ondas eletromagnéticas, assim como o próprio corpo humano em suas funções bioquímicas produzir ondas magnéticas, mesmo que fracas e em muito baixa frequência, somos especialmente sensíveis à radiação eletromagnética produzida artificialmente pelas linhas de transmissão, equipamentos elétricos, torres de telefonia móvel e aparelhos de celulares. Tais espécies de ondas nos cercam a cada instante do dia, poluindo tanto o ambiente interno, das residências, quanto o ambiente externo, principalmente nas grandes metrópoles.

Conforme explanou-se ao longo do texto, estando as pessoas cercadas e bombardeadas a todo instante por ondas eletromagnéticas que poluem o meio ambiente cada dia mais, consideráveis são as possibilidades de danos à saúde dos seres humanos. Diversos estudos têm sido desenvolvidos no intuito de averiguar e/ou confirmar as possibilidades reais de danos à saúde decorrentes da exposição humana à poluição eletromagnética

Inúmeros são os estudos já desenvolvidos e em realização que examinam a possibilidade da ação dos campos eletromagnéticos resultar em danos biológicos e à saúde humana, máxime com o uso de telefones celulares e a exposição da população a fontes irradiadoras, como as estações rádio-base [torres de telefonia móvel], que se multiplicam de maneira extraordinária, a cada dia, nas paisagens urbanas (BATISTA, 2008, p. 74) 
Relatou o autor da ação que existem preocupações de diversas pessoas e entidades civis quanto aos riscos à saúde humana em função das radiações eletromagnéticas emitidas por torres de telefonia celular, especialmente aquela instalada no Bairro das Acácias, município de Capelinha/MG. Em decorrência desta preocupação, houve até abaixo assinado da comunidade à Promotoria de Justiça. Em decorrência disso, foi instaurado um inquérito civil de $n^{\circ}$ 0123.05.000001-7, "tendo esta ação civil pública como objetivo a retirada da antena da área residencial na qual se encontra" (TJMG, 2014). Nessa ação civil pública, explicou-se com detalhes qual seria a nocividade da presença da torre de telefonia naquele bairro instalada, "explicando que há estudos científicos que apontam a efetiva possibilidade da radiação eletromagnética, oriunda de estações de rádio base, produzir efeitos biológicos potencialmente nocivos à saúde humana sob exposição contínua e a longo prazo." (TJMG, 2014)

Foi então que o Ministério Público do Estado de Minas Gerais interpôs recurso de apelação à decisão de primeira instância, da comarca que Capelinha que "julgou improcedentes os pedidos formulados na inicial, extinguindo o processo, com resolução do mérito, nos termos do art. 269, I do CPC. Não houve condenação em custas e honorários." (TJMG, 2014)

O MP-MG, utilizou-se do argumento de que o princípio da precaução ${ }^{7}$ em matéria de direito ambiental traz como exigência que, em havendo dúvida com bases científicas quanto à existência de riscos intrínsecos a determinada atividade, é obrigatório a adoção de medidas economicamente viáveis que possam evitar o dano, na forma de poluição eletromagnética, em potencial. "Discorre sobre os efeitos térmicos da radiação não ionizante trazendo relatórios e estudos realizados. Transcreve jurisprudências e baseia-se nos direitos à saúde e ao meio ambiente ecologicamente equilibrado para pretender a reforma da sentença" (TJMG, 2014)

O Tribunal de Justiça de Minas Gerais, por meio da $5^{\mathrm{a}}$ Câmara Cível, reconheceu o recurso interposto pelo Ministério Público do Estado de Minas Gerais, entretanto, entendeu que não assistia razão ao autor/recorrente. Começa o acórdão utilizando, como argumento, a existência por parte da estação de rádio base (ou torre de telefonia celular) de todo o amparo

\footnotetext{
${ }^{7}$ Em linhas gerais, o princípio da precaução corresponde ao dever de cautela para com os riscos incertos cientificamente, gerados por uma determinada atividade ou empreendimento (NAVES; SILVA, 2014, p. 369) 


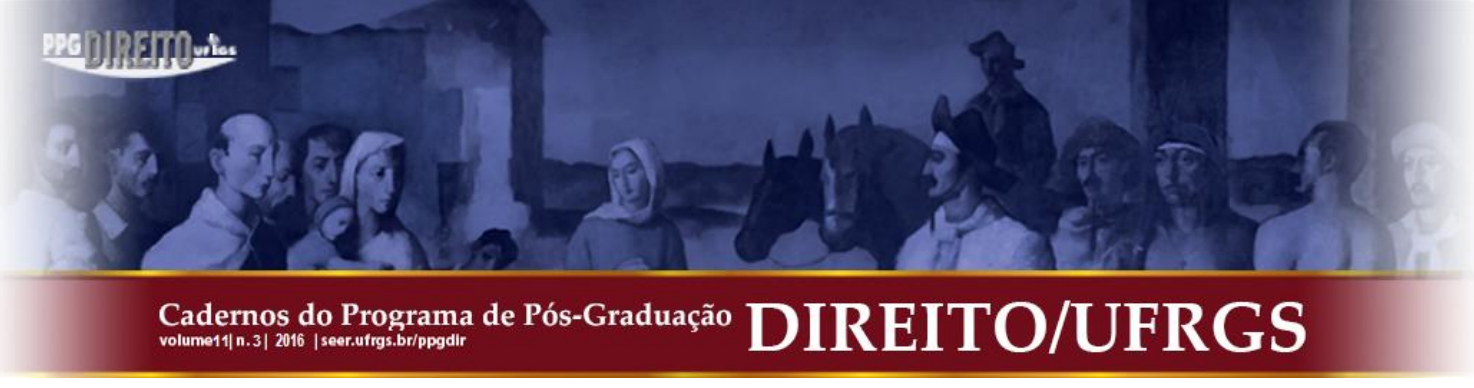

organismos que se mostram mais sensíveis a partir do momento em que esse sistema biológico vê-se sobrecarregado para além de sua capacidade natural de compensação das radiações absorvidas. Quando organismos mais sensíveis são expostos continuamente à ondas eletromagnéticas, tal exposição pode gerar modificações funcionais ou mesmo estruturais no organismo. Entretanto, afirmou a decisão que

Considerando os níveis muito baixos de exposição e os resultados das pesquisas reunidos até o momento, não existe evidência científica convincente de que os fracos sinais de RF provenientes de estações rádio-base e de redes sem fio, causem efeitos adversos à saúde.

Diante de todo o exposto, deixou o autor de fazer prova robusta das alegações apontadas na exordial, não podendo a tutela jurisdicional se basear exclusivamente em suposições da população interessada. (TJMG, 2014)

A contrario sensu do afirmado pela decisão do Tribunal de Justiça, a presença de estudos tendentes tanto para a não maleficência das estações de rádio-base, quanto aqueles que apresentam casos de alterações na saúde daqueles expostos às suas micro-ondas, faz nascer certa incerteza no campo científico que acaba por migrar para o campo jurídico. Desta forma não seria possível a utilização do princípio da prevenção para embasar os argumentos aqui apresentados, vez que

Na prática, o princípio da prevenção tem como objetivo impedir a ocorrência de
danos ao meio ambiente, através da imposição de medidas acautelatórias, antes da
implantação de empreendimentos e atividades consideradas efetiva ou
potencialmente poluidoras. (MILARÉ, 2015, p. 264)

Entretanto, se tomar-se como base o princípio da precaução, sagrado na Declaração do Rio - ECO 1992 que, mesmo não possuindo natureza jurídica de um tratado internacional para o Estado brasileiro, traz diretrizes éticas a serem seguidas por todos os países signatários. Desta feita, nos casos em que se vislumbre um perigo ambiental, um perigo à saúde humana “[...] será recomendável que o Poder Público não libere a atividade supostamente impactante até que haja uma evolução científica a fim de melhor analisar a natureza e a extensão dos potenciais males ambientais, pois é possível que não seja prudente arriscar" (AMADO, 2013, p. 58). Portanto, a existência de estudos que apontam em ambas as direções, quais sejam, a inexistência de riscos à saúde humana frente a baixa exposição, bem como alterações físicas e surgimento de doenças atribuídos à exposição contínua às ondas eletromagnéticas, expõe um 


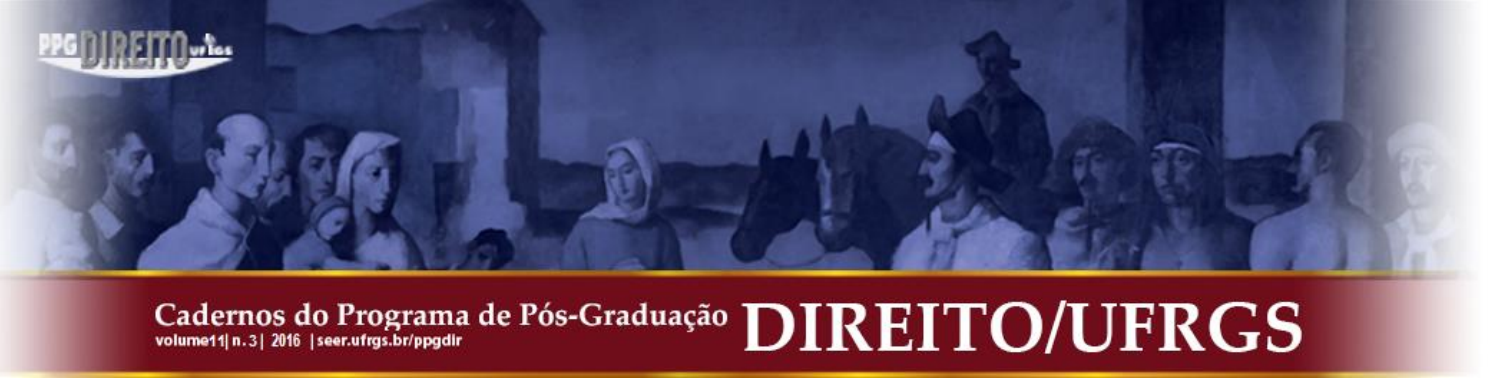

nível de incerteza científica que pende em favor do meio ambiente e da saúde humana. É característica do princípio da precaução a antecipação das ações ante o risco incógnito.

Não há como saber, com total certeza, se existe um nível mínimo de exposição seguro para a saúde humana, "o conhecimento científico disponível na literatura especializada internacional aponta para a incerteza quanto a um nível mínimo de exposição à radiação não ionizante conhecido que garanta proteção à saúde humana” (PADUELI; GOUVEIA, 2010, p. 4). Não havendo a certeza de um nível mínimo de exposição seguro à saúde humana e, sendo a tecnologia baseada nas ondas eletromagnéticas tão essencial à vida moderna, encontramonos em um verdadeiro impasse. Nos últimos vinte anos, diversos estudos foram realizados acerca das alterações físiológicas causadas pela exposição à radiação eletromagnética, de maneira constante. Nesses estudos, avaliou-se os efeitos quanto à alteração biofísica daqueles que são expostos, bem como seus efeitos para a saúde dos organismos.

En los últimos veinte años, programas de investigación en todo el mundo han realizado avances significativos em la caracterización las interacciones posibles de los CEM y los organismos vivos, destacando los estudios sobre los efectos biológicos de los CEM y los mecanismos biofísicos implicados em tales efectos. También se há profundizado em la cuestión de la relevancia que los efectos biológicos de los CEM detectados experimentalmente tienen para la salud. ${ }^{9}$ (CAMPOS, 1999, p. 12)

Para alguns estudiosos os danos decorrentes da exposição às ondas eletromagnéticas dividem-se em dois grupos distintos: aqueles danos claramente conhecidos e reconhecidos e os danos sobre os quais há controvérsias. No grupo dos danos claramente conhecidos e reconhecidos podemos destacar o aumento da temperatura corporal, causado pela radiação de alta frequência, neste caso "o efeito é semelhante ao da febre e resulta na redução da atividade mental e em problemas na irrigação sanguínea" (BOITEUX, E.; BOITEUX, NETTO, 2008, p. 37-38). Pode-se acrescentar ainda, a esse grupo, as alterações que a exposição às ondas pulsadas ou micro-ondas acabam por causar ao ser humano.

De acordo com Lopes (2014) há estudos que vêm demonstrando o malefício da poluição eletromagnética, causando efeitos adversos na tireoide, assim como nos hormônios sexuais tanto masculinos quanto femininos. Da mesma forma, a radiação proveniente dos

\footnotetext{
${ }^{9}$ Nos últimos vinte anos, programas de pesquisa em todo o mundo realizaram avanços significativos na caracterização das interações possíveis entre os CEM e os organismos vivos, destacando os estudos sobre os efeitos biológicos dos CEM e os efeitos biofísicos implicados em tais efeitos. Também aprofundou-se na questão da relevância que os efeitos biológicos do CEM detectados experimentalmente têm para a saúde. (tradução nossa)
}

Cadernos do Programa de Pós-Graduação em Direito PPGDir./UFRGS | Edição Digital | Porto Alegre | Volume XI | Número 3 | 2016 | P. 80 - 98 


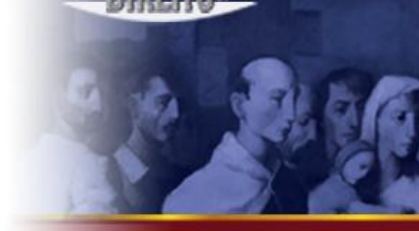

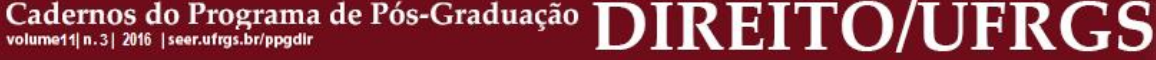

sistemas de telecomunicações afetam o hormônio do tipo insulina, responsável por controlar os níveis de açúcar no sangue. Nesse mesmo grupo, dos danos conhecidos e reconhecidos, pode-se incluir aqueles causados pelas ondas de baixa frequência que podem causar impulsos nervosos e musculares involuntários e "essas contrações podem causar um simples desconforto, mas também podem ser fatais" (BOITEUX, E.; BOITEUX, NETTO, 2008, p. $38)$.

Entretanto, ainda argumentando acerca do ônus probatório e da impossibilidade do Ministério Público do Estado de Minas Gerais de provar a possibilidade de danos à saúde daqueles que vivem próximos à radio-base no bairro das Acácias em Capelinha/ MG trazem os desembargadores a seguinte argumentação e sua conclusão sobre a contenda

A regra, destarte, é que independentemente da posição no processo cada parte venha a provar os fatos constitutivos do próprio direito, bem como os impeditivos, modificativos ou extintivos do direito alheio, do que decorrem importantes consequências particularmente quanto a ações incidentais de cunho impugnativo, como os embargos do devedor, na execução (v. arts. 736, 741 e 745), ou os embargos ao mandado, na ação monitória (v. art. 1.102c). Pois bem, por fatos constitutivos do direito - não importando de qual parte -, devem ser entendidos aqueles tomados como base para a afirmação de um direito de que se imagine ela titular, e que pretenda ver reconhecido em juízo (assim, a existência da locação e a ocorrência de fato ou circunstância tidos por lei como autorizadores da retomada, em ação de despejo, a ocorrência de ato ilícito praticado pela outra parte e o prejuízo dele decorrente, em ação indenizatória). Já quanto aos fatos impeditivos, modificativos ou extintivos, impõe-se maior cautela, pois não se confundem eles com a mera negativa dos fatos aduzidos pela parte adversa" (Código de Processo Civil Interpretado, coordenador Antônio Carlos Marcato, São Paulo: Atlas, 2004, p. 1.000).

Firme em tais considerações, nego provimento ao recurso, mantenho inalterada a sentença. (TJMG, 2014)

Todavia, contrariando o afirmado no acórdão em comento, no que se refere aos danos comprovados, causados pela exposição à radiação, conforme aponta Lopes (2014), como grande ironia à tecnologia voltada para telecomunicações e as micro-ondas por eles emitidas parece causar interferência no que seria o sistema natural de comunicação existente entre nossas células. As micro-ondas eletromagnéticas emitidas pelo uso e funcionamento dos aparelhos de comunicação, em especial aqueles que são utilizados muito próximo de nosso corpo, afetaria os íons de cálcio existentes em nosso organismo e são eles os principais responsáveis pelo transporte de informações, dentro e fora de nossas células. Segundo o que dispõe Lopes (2014) a contínua exposição à $\operatorname{REM}^{10}$ causaria um tipo de excitação no

\footnotetext{
${ }^{10}$ R.E.M: sigla utilizada para denominar “radiação eletromagnéticas”. Explicação do autor.
} 


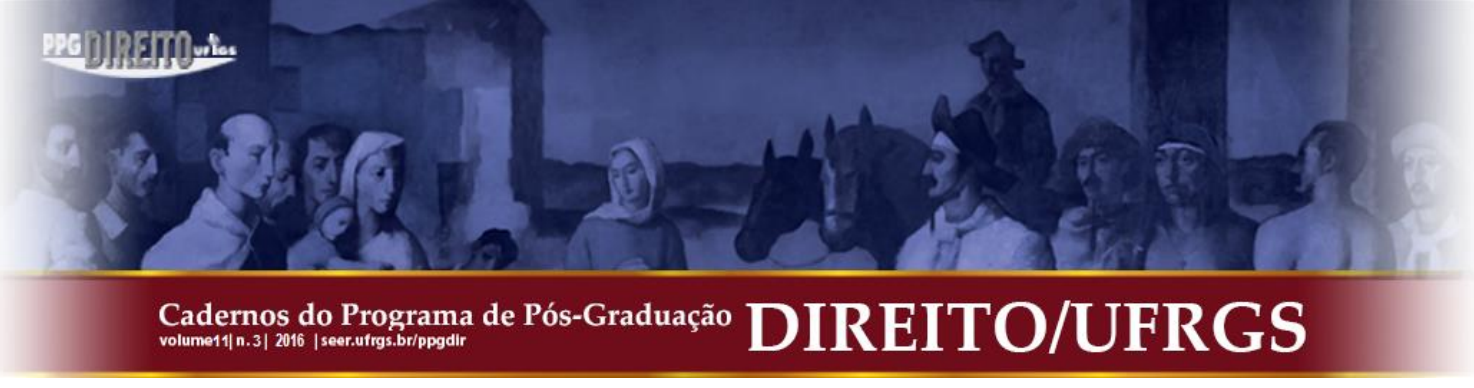

chamado ácido glutâmico, ou glutamato, que se mostra um importante aminoácido que age como neurotransmissor, e esta excitação pode vir a alterar os padrões cerebrais.

Da mesma forma, um estudo da feito por um membro da Comissão Nacional de Energia Nuclear, afirma que a exposição contínua à radiação pode provocar a morte celular. Mais especificamente

Células cuja taxa de divisão é alta, tornam-se mais vulneráveis à ação das radiações. Quando uma lesão no DNA resultar quebra da molécula, a célula passa a ter dificuldade em dividir o material genético entre as células filhas, que podem morrer após uma ou duas divisões subsequentes. (NOUAILHETAS, s/a, p. 30)

No que tange às modificações causadas ao organismo humanos, Claudio Viveiros de Carvalho, citando dados da Organização Mundial de Saúde e informações de Dias \& Siqueira, afirma que

Também a radiação não ionizante interfere no funcionamento do organismo humano; ela induz a formação de correntes e campos elétricos e magnéticos em seu interior. Dependendo de sua amplitude e frequência, pode causar aquecimento ou choques eléctricos, por exemplo, ou mesmo alterar o padrão de excitabilidade das células musculares e nervosas. Usualmente esses efeitos são divididos em térmicos e não térmicos (OMS 2012; OMS 2017; DIAS \& SIQUEIRA, 2012 p. 5)

No grupo dos danos sobre os quais há controvérsias, as doenças foram atribuídas à exposição aos campos eletromagnéticos, no entanto, os estudos feitos sobre o tema ainda não conseguiram chegar a um consenso acerca do tema, uma vez que existem pesquisas tanto negando quanto confirmando tais hipóteses, o que dificulta e muito os meios de prova quanto às causas. Seriam as doenças ou quadros clínicos a

Leucemia em adultos e em crianças; câncer no cérebro de adultos e crianças; câncer de mama em homens e mulheres; aborto espontâneo;

esclerose lateral amiotrófica; mal de Alzheimer; infarto agudo do miocárdio; suicídio. (BOITEUX, E.; BOITEUX, NETTO, 2008, p. 42-43).

Sejam problemas de saúde claramente reconhecidos, sejam problemas que ainda possuem controvérsias, quanto à sua comprovação, é certo que a exposição humana a ondas eletromagnéticas é algo potencialmente nocivo à saúde e, tendo em vista o nível de poluição eletromagnética a que nos vemos expostos todos os dias, as consequências podem ser desastrosas a longo prazo. Dessa forma, necessário se faz buscar meios de diminuir a emissão de tais ondas, assim como de responsabilizar as empresas emissoras caso sejam comprovados os danos à saúde decorrentes da poluição eletromagnética. 


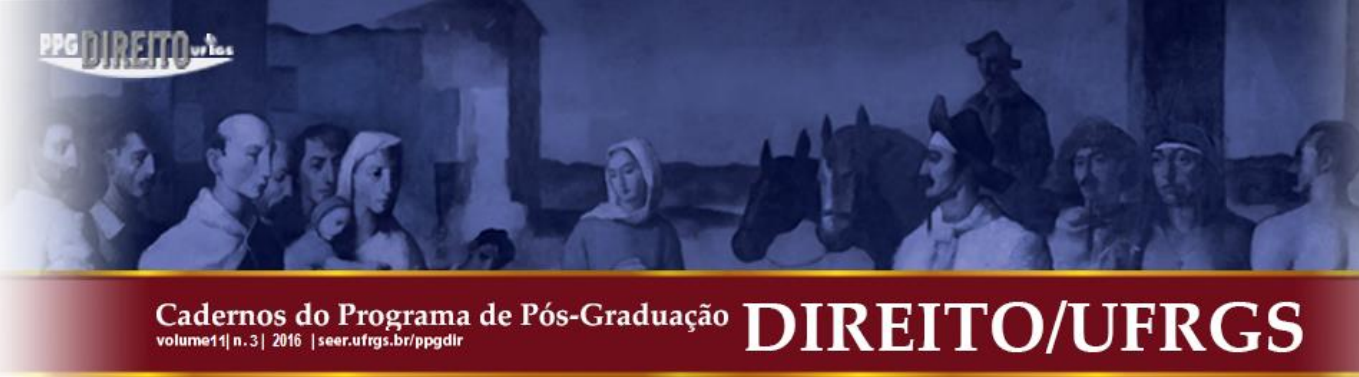

Portanto, a decisão do Tribunal de Justiça de Minas Gerais, em negar provimento ao recurso de apelação interposto pelo Ministério Público de Minas Gerais a fim de retirar do bairro residencial a radio-base traz potenciais riscos à saúde daqueles que moram próximos a área em que se localiza a torre e não possuem condições de se retirarem.

\section{CONSIDERAÇÕES FINAIS}

Com a tecnologia se tornando parte essencial do dia a dia humano, novos aparelhos sendo adquiridos a cada segundo, certo é que a emissão de ondas eletromagnéticas só tende a aumentar nos próximos anos.

Não restam dúvidas, tendo em vista os estudos e trabalhos realizados acerca do tema, que as ondas eletromagnéticas emitidas pelos aparelhos elétricos, as torres de alta tensão, as torres de telefonia móvel poluem o ambiente.

Assim, após apresentação de abaixo assinado da comunidade à promotoria de justiça, o Ministério Público ajuizou ação civil pública a fim de retirar do bairro das Acácias, na cidade de Capelinha/MG uma rabio-base, sob a alegação de possíveis danos à saúde daqueles que residiam em áreas próximas.

Em sentença de primeiro grau, o juiz de Capelinha negou provimento ao pedido do MP-MG sob o argumento de não ter ficado comprovado a possibilidade de danos, vez que os dados fornecidos pela ANATEL demonstravam a baixa intensidade das ondas eletromagnéticas emitidas pela rádio-base.

Em acórdão de segunda instância, mantendo argumentação semelhante, afirmando não ter o MP-MG comprovado os riscos à saúde e, tendo a ANATEL fornecido informações suficientes que comprovassem a inocuidade das ondas eletromagnéticas emitidas pela rádiobase, para a saúde humana, manteve-se a decisão de primeira instância, negando provimento ao recurso de apelação.

Entretanto, por meio de estudos foi possível comprovar que nem mesmo dentro das residências se está livre da poluição eletromagnética proveniente de aparelhos utilizados a todo momento. Da mesma forma, continuamente, de forma voluntária, o organismo humano absolve pulsos eletromagnéticos, em forma de microondas, advindos do uso constante dos aparelhos celulares. 


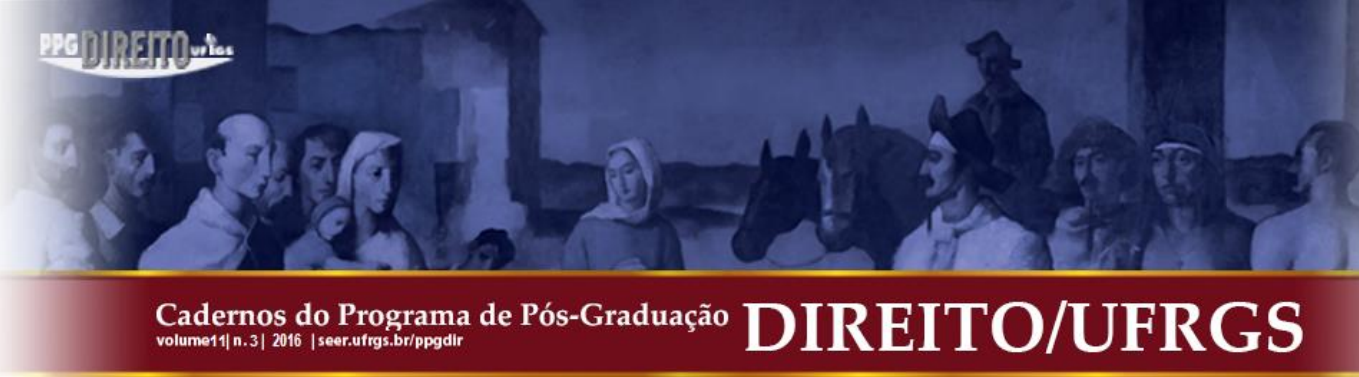

Há pessoas, cujo organismo se demonstra mais sensível à exposição às ondas eletromagnéticas e, portanto, convivem com a poluição advinda das torres de alta tensão e radio-bases, e portanto, acabam por desenvolver determinados tipos de doenças como câncer e Alzheimer.

No entanto, muito ainda deve-se avançar quando o assunto são os estudos e pesquisas sobre os malefícios provocados pelas ondas eletromagnéticas. Diversos estudos foram desenvolvidos ao longo dos anos, mas poucas respostas concretas foram encontradas.

\section{REFERÊNCIAS}

AMADO, Frederico. Direito Ambiental Esquematizado. São Paulo: Método Editora, 2013.

ALMEIDA, Daniela Scaranello Elias. A Tutela Ambiental Referente à Poluição Eletromagnética Advinda das Estações de Rádio Base da Telefonia Móvel Pessoal. (Dissertação de Mestrado). Universidade Metodista de Piracicaba. 2010. Disponível em: $<$ https://www.unimep.br/phpg/bibdig/pdfs/docs/06072011_114142_danielascaranelloeliasdeal meida.pdf $>$. Acesso em: 30 abr. 2016.

BATISTA, Roberto Carlos. Poluição eletromagnética: telefonia celular, risco sanitário ambiental e precaução. Boletim Científico. Escola Superior do Ministério Público Federal. Brasília. a.7. n. 26. 2008.

BEDRAN, Karina Marcos; MAYER, Elizabeth. A RESPONSABILIDADE CIVIL POR DANOS AMBIENTAIS NO DIREITO BRASILEIRO E COMPARADO: Teoria do Risco Criado versus Teoria do Risco Integral. Revista Veredas do Direito. Belo Horizonte. v.10. n.19. 2013. p.45-88.

BOITEUX, Elza Antônia P. C; BOITEUX, Fernando Netto. Poluição eletromagnética e meio ambiente: o princípio da precaução. Porto Alegre: Sérgio Antonio Fabris Editor, 2008.

BRASIL. Constituição (1988). Constituição da República Federativa do Brasil.

Disponível em: <http://www.planalto.gov.br/ccivil_03/Constituicao/Constituiçao.htm>. Acesso em: 03 maio 2016. 


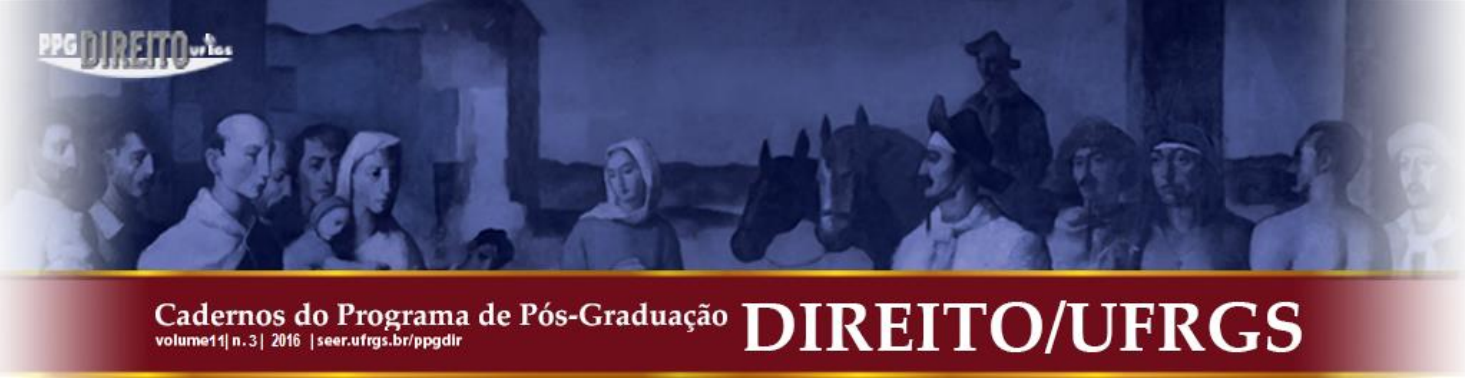

CARVALHO, Cláudio Viveiros de. Radiação eletromagnética e saúde. Câmara dos Deputados - consultoria legislativa, 2012. Disponível em: http://www2.camara.leg.br/documentos-e-pesquisa/publicacoes/estnottec/areas-daconle/tema19/2012_14229.pdf. Acesso em: 03 de nov. 2016.

LOPES, Eugênio. Que Futuro!!! Os efeitos da poluição eletromagnética sobre a saúde. São Paulo: Schoba. 2014. Livro em formato E-book.

MARCOS, Francisco Vargas. Riesgos para la salud humana de las exposiciones ambientales a campos eléctricos y magnéticos. Fisica y sociedad. n.10. 1999. Disponível em: $<$ http://www.etsist.upm.es/estaticos/catedracoitt/web_salud_medioamb/Informes/informes_PDF/camposelectromagneticos/CamposEM ySaludPublica.pdf>. Acesso em: 22 de maio de 2016.

MINAS GERAIS, Tribunal de Justiça. Apelação Cível. Ap 1.0123.10.038116-9/002. Relator Fernando Caldeira Brant. Súmula publicada em 29/08/2014. Disponível em: < http://www5.tjmg.jus.br/jurisprudencia/pesquisaPalavrasEspelho Acordao.do?paginaNumero= $3 \&$ linhasPorPagina $=1 \&$ numeroRegistro $=3 \&$ totalLinhas $=3 \&$ palavras $=$ eletromagn $\%$ E9tica\&pe squisarPor $=$ ementa\&pesquisaTesauro $=$ true \&orderByData $=1 \&$ referenciaLegislativa $=$ Clique $\%$ 20na $\% 201$ upa $\% 20$ para $\% 20$ pesquisar $\% 20$ as $\% 20$ refer $\%$ EAncias $\% 20$ cadastradas...\&pesquisaPa lavras $=$ Pesquisar\& $>$. Acesso em: 05 maio. 2016.

MORAES, Vivian Lacerda. Os danos punitivos na responsabilidade civil por danos morais no direito brasileiro. In Temas de Direito Público e Privado. Belo Horizonte: Arraes, 2014. p. 397-410.

MILARÉ, Edis. Direito do Ambiente. São Paulo: Revista dos Tribunais, 2015.

NAVES, Bruno Torquato de Oliveira; SILVA, Marcela Vitoriano. Organismos geneticamente modificados sob a perspectiva da tutela das gerações futuras. Revista Veredas do Direito. Belo Horizonte. v.11. n. 22. 2014. p. 355-380

NOUAILHETAS, Yannik. Radiações Ionizantes e a vida. Cnen - Comissão Nacional de Energia Nuclear: apostila educativa. s/a. Disponível em: http://www.cnen.gov.br/images/cnen/documentos/educativo/radiacoes-ionizantes.pdf. Acesso em: 06 nov. 2016. 


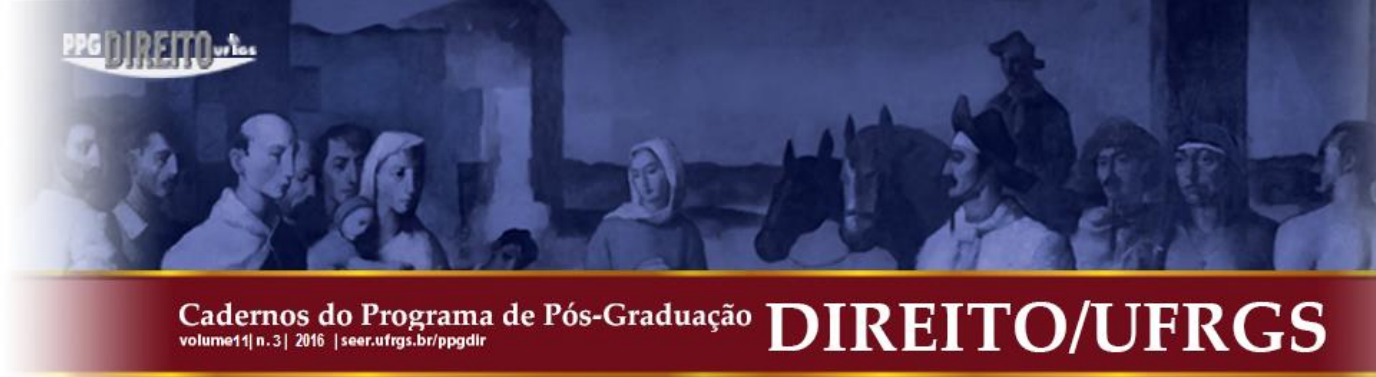

PADUELI, Margaret Ponce; GOUVEIA Nelson. A telecomunicação móvel e a poluição eletromagnética. Revista de Gestão Integrada em Saúde do Trabalho e Meio Ambiente. V.5. n. 10. 2010.

RIO GRANDE DO SUL. Universidade do Federal do Rio Grande do Sul. Centro Estadual de Pesquisas em Sensoriamento Remoto e Meteorologia). Disponível em: http://www.ufrgs.br/engcart/PDASR/rem.html. Acesso em: 03 de maio de 2016.

. Universidade Federal do Rio Grande do Sul. Instituto de física. Disponível em: $\overline{<h t t p: / / w w w . i f . u f r g s . b r / o e i / c g u / e s p e c / i n t r o . h t m>. ~ A c e s s o ~ e m: ~} 01$ maio 2016.

Submissão: 20/06/2016

Aceito para Publicação: 03/01/2017 


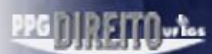

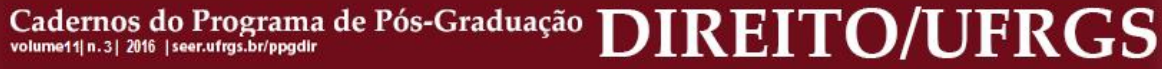

98 